\title{
Comparison of DNA-Lipid Complexes and DNA Alone for Gene Transfer to Cystic Fibrosis Airway Epithelia In Vivo
}

\author{
Joseph Zabner, ${ }^{\star}$ Seng H. Cheng, ${ }^{\ddagger}$ David Meeker, ${ }^{\ddagger}$ Jan Launspach, ${ }^{\star}$ Rosemary Balfour, ${ }^{\ddagger}$ Michael A. Perricone, ${ }^{\ddagger}$ \\ James E. Morris, ${ }^{\ddagger}$ John Marshall, ${ }^{\ddagger}$ Al Fasbender, ${ }^{\star}$ Alan E. Smith, ${ }^{\ddagger}$ and Michael J. Welsh* \\ *Howard Hughes Medical Institute, Departments of Internal Medicine and Physiology and Biophysics, University of Iowa College of \\ Medicine, Iowa City, Iowa 52242; and ${ }^{\ddagger}$ Genzyme Corporation, Framingham, Massachusetts 01701
}

\begin{abstract}
Cationic lipids show promise as vectors for transfer of CFTR cDNA to airway epithelia of patients with cystic fibrosis (CF). However, previous studies have not compared the effect of DNA-lipid to DNA alone. Recently, we developed a formulation of plasmid encoding CFTR (pCF1CFTR) and cationic lipid (GL-67:DOPE) that generated greater gene transfer in mouse lung than previously described DNA-lipid vectors. Therefore, we tested the hypothesis that DNA-lipid complexes were more effective than DNA alone at transferring CFTR cDNA to airway epithelia in vivo. We administered complexes of DNA-lipid to one nostril and DNA alone to the other nostril in a randomized, double-blind study. Electrophysiologic measurements showed that DNA-lipid complexes partially corrected the $\mathrm{Cl}^{-}$ transport defect. Importantly, the pCF1-CFTR plasmid alone was at least as effective as complexes of DNA with lipid. Measurements of vector-specific CFTR transcripts also showed gene transfer with both DNA-lipid and DNA alone. These results indicate that nonviral vectors can transfer CFTR cDNA to airway epithelia and at least partially restore the $\mathrm{Cl}^{-}$transport defect characteristic of CF. However, improvements in the overall efficacy of gene transfer are required to develop a treatment for CF. (J. Clin. Invest. 1997. 100:1529-1537.) Key words: gene transfer • cystic fibrosis $\bullet$ epithelia $\bullet$ airway $\cdot$ CFTR $\cdot$ chloride channel
\end{abstract}

\section{Introduction}

The loss of CFTR $\mathrm{Cl}^{-}$channel function in airway epithelia causes lung disease, the major source of morbidity and mortality in cystic fibrosis $(\mathrm{CF})^{1}(1)$. Although current treatments have improved the lives of patients with $\mathrm{CF}$, there is presently no treatment that is directed at the underlying defect and $\mathrm{CF}$ remains a lethal disease. Recently, several efforts have been

Address correspondence to Michael J. Welsh, M.D., Howard Hughes Medical Institute, University of Iowa College of Medicine, 500 EMRB, Iowa City, IA 52242. Phone: 319-335-7619; FAX: 319-3357623; E-mail: mjwelsh@blue.weeg.uiowa.edu

Received for publication 10 April 1997 and accepted in revised form 24 June 1997.

1. Abbreviations used in this paper: $\mathrm{CF}$, cystic fibrosis; Vt, voltage across the nasal epithelium.

J. Clin. Invest.

(c) The American Society for Clinical Investigation, Inc. 0021-9738/97/09/1529/09 \$2.00

Volume 100, Number 6, September 1997, 1529-1537

http://www.jci.org directed at developing gene transfer to airway epithelia as a potential treatment.

To date, recombinant adenovirus vectors have received the most attention. Studies in humans have shown that adenovirus vectors encoding CFTR can express the transgene in airway epithelia and can at least partially correct the $\mathrm{CF}$ defect in electrolyte transport (2-5). However, there are several limitations to adenovirus-mediated gene transfer. First, the efficiency of gene transfer to uninjured airway epithelia is low (4-6). Second, because gene transfer to airway epithelia is transient, the use of recombinant adenovirus vectors will require repeat administration. The requirement for repeat administration is a concern because in both animals and humans, administration of high doses of adenovirus can generate neutralizing antibodies which can limit subsequent gene transfer. Furthermore, administration of high doses of adenovirus vectors can generate an inflammatory response.

In vitro studies have shown that cationic lipids can also affect gene transfer to cells including airway epithelia. Most studies have focused on administration of DNA-cationic lipid complexes via the airways. This mode of administration has the advantage that the target cells are in contact with the airway lumen and gene transfer to other organs is minimized. Several in vitro experiments have been performed in animals. Stribling et al. (7) reported that aerosol delivery of DNA complexed to $N$-[1-(2,3-dioleoyloxy)propyl]-n,n,n-trimethylammonium chloride (DOTMA):dioleoyl phosphatidylethanolamine (DOPE) produced gene transfer to the majority of airway epithelia and alveolar cells. Canonico et al. (8) showed significant expression of transgene in the lungs after aerosol delivery of DOTMA:DOPE complexed with DNA. In addition, Alton et al. (9) and Hyde et al. (10) found that complexes of $\left[N-\left(N^{\prime}, N^{\prime}\right.\right.$-dimethylaminoethane)carbamoyl]cholesterol (DCChol):DOPE with a plasmid encoding CFTR were able to correct the $\mathrm{CF}$ electrophysiologic defect in mice in which the CFTR gene had been disrupted. It is important to note that some studies done in mice lungs have shown equal efficacy of gene transfer by plasmid DNA alone compared with plasmid complexed to DOTMA-DOPE, $N$-[1-(2,3-dioleoyloxy)propyl]- $N, N, N$-trimethyl-ammoniummethylsulfate (DOTAP), and DDAB $(11,12)$. Three studies in humans have been reported. In the first, human trial complexes of DNA and DC-Chol: DOPE appeared to be safe when administered to the nasal epithelia of patients with CF (13). Two subsequent studies using DC-Chol:DOPE and DOTAP have been reported recently $(14,15)$. However, in all cases the degree to which the CF electrophysiologic defect was corrected was small and variable. Just as with adenovirus vectors, the efficiency of gene transfer in that study was suboptimal.

To develop a more efficient nonviral cationic lipid vector system, Lee et al. (16) took a systematic approach to evaluate gene transfer using administration to the lungs of mice in vivo. Most of the commercially available cationic lipids showed a lim- 
ited ability to enhance transgene expression when compared with DNA alone. However, a novel lipid, (3-amino-propyl)[4(3-amino-propylamino)-butyl]-carbamic acid 17-(1,5-dimethylhazyl)-10,13-dimethyl-2,3,4,7,8,9,10,11,12,13,14,15,16,17-tetradecahydro-1H-cyclopenta $[\alpha]$ phenanthren-3yl ester (GL-67) in combination with the neutral colipid DOPE, enhanced gene transfer by $>1,000$-fold as compared with DNA administered alone. Furthermore, complexes of DNA with GL-67:DOPE were found to be safe and stable. Those results suggest that the cationic lipid GL-67:DOPE is more efficient than previously tested lipids for gene transfer to lung. Specifically, the data predicted improvement as compared with DC-Chol:DOPE which had been previously used in a human study (13).

The present work was designed for two purposes. First, we evaluated whether complexes of DNA with GL-67:DOPE were safe when administered to the airway epithelium of humans. Second, we tested the hypothesis that complexes of DNA with GL-67:DOPE could transfer the CFTR cDNA to the airway epithelium and correct the electrophysiologic defect. For these studies we used the nasal epithelium because it provides a model of the intrapulmonary epithelium and is readily accessible for delivery of the vector and for assessment of toxicity and electrophysiologic correction. As a control we compared the efficacy of DNA-cationic lipid complexes to DNA administered alone.

\section{Methods}

Reagents. The lipid was composed of a 1:2 molar ratio of the cationic lipid GL-67 and the neutral lipid DOPE (16). CFTR cDNA was encoded by the plasmid pCF1-CFTR. pCF1-CFTR was based on the commercially available vector $\mathrm{pCMV} \beta$ (Clontech, Palo Alto, CA). It contains the human cytomegalovirus immediate early gene promoter and enhancer, followed by the tripartite leader from adenovirus, a hybrid intron, the CFTR cDNA, and a polyadenylation signal from bovine growth hormone. An identical plasmid without CFTR cDNA (pNull) was used as a negative control in some subjects.

Subjects. We studied six non-CF subjects who ranged in age from 23 to 41 yr. 12 CF subjects participated in the study. The characteristics are shown in Table I.

Study design and vector administration. The protocol was designed as a single administration, randomized, double-blind study. The pro-

Table I. Characteristics of Participants

\begin{tabular}{|c|c|c|c|c|c|c|}
\hline Subject & Sex & Age & CF mutation & $\begin{array}{c}\text { FEV1 } \\
\text { (\% predicted) }\end{array}$ & $\begin{array}{c}\text { Sweat } \\
\mathrm{Cl}^{-}\end{array}$ & $\begin{array}{l}\text { Pancreatic } \\
\text { function }\end{array}$ \\
\hline LC01 & M & 24 & P67L/Q493X & 72 & 59 & PS \\
\hline $\mathrm{LC} 02$ & M & 29 & $? / \Delta \mathrm{F} 508$ & 53 & 111 & PI \\
\hline $\mathrm{LC} 03$ & M & 26 & $\Delta \mathrm{F} 508 / \Delta \mathrm{F} 508$ & 66 & 81 & PI \\
\hline $\mathrm{LC} 04$ & $\mathrm{~F}$ & 53 & $\Delta \mathrm{F} 508 / \Delta \mathrm{F} 508$ & 41 & 108 & PI \\
\hline LC05 & M & 28 & $\Delta \mathrm{F} 508 / \Delta \mathrm{F} 508$ & 49 & 96 & PS \\
\hline LC06 & M & 20 & $\Delta \mathrm{F} 508 / \mathrm{A} 455 \mathrm{E}$ & 98 & 63 & PS \\
\hline $\mathrm{LC} 07$ & M & 31 & $3849+10 / \Delta \mathrm{F} 508$ & 44 & 26 & PS \\
\hline LC08 & M & 39 & $\Delta \mathrm{F} 508 / 6551 \mathrm{D}$ & 56 & 67 & PI \\
\hline LC09 & $\mathrm{F}$ & 18 & $\Delta \mathrm{F} 508 / \Delta \mathrm{F} 508$ & 33 & 115 & PI \\
\hline LC10 & M & 30 & $\Delta \mathrm{F} 508 / \mathrm{R} 347 \mathrm{H}$ & 70 & 67 & PS \\
\hline LC11 & $\mathrm{F}$ & 29 & $\Delta \mathrm{F} 508 / \Delta \mathrm{F} 508$ & 39 & 78 & PI \\
\hline LC12 & $\mathrm{F}$ & 18 & $\Delta \mathrm{F} 508 / \Delta \mathrm{F} 508$ & 52 & 78 & PI \\
\hline
\end{tabular}

For CF mutation, ? refers to an unknown mutation. PS and PI refer to pancreatic sufficient and pancreatic insufficient, respectively. tocol was approved by the University of Iowa Institutional Review Board and Institutional Biosafety Committee. It was also reviewed by the Office of the National Institutes of Health Recombinant DNA Advisory Committee and the Food and Drug Administration. Timing of evaluations was designed to detect acute changes in nasal epithelia voltage after vector administration. Assays were performed on at least two pretreatment days and then on days 1-4 and day 21 after treatment. Subjects received vector while seated; no anesthetics or vasoconstrictors were used. We applied the reagents to the nasal epithelium using a size 8 Foley catheter (modified with a wedge shape cut proximal to the balloon) which was introduced under endoscopic guidance to the nasal mucosa. The catheter was positioned beneath the inferior turbinate, $6 \mathrm{~cm}$ from the most caudal aspect of the columella. All vectors were slowly infused at a rate of $12.5 \mu \mathrm{l} / \mathrm{min}$ over $80 \mathrm{~min}$.

The study was designed in three parts. In part A, we tested the safety and effect on transepithelial voltage of administering the cationic lipid formulation alone. This part of the study was performed on non-CF subjects and sterile water was used as a control. In part B, CF subjects received $1.25 \mathrm{mg}$ of pCF1-CFTR alone to one nostril and $1.25 \mathrm{mg}$ pCF1-CFTR complexed with $2 \mathrm{mg}$ GL-67:DOPE to the other nostril. In part C, CF subjects received $1.25 \mathrm{mg}$ of pCF1-CFTR to one nostril and $1.25 \mathrm{mg}$ of pNull to the other nostril. Data from all 18 subjects were evaluated in a blinded fashion.

Clinical assessments. Participants were studied on two pretreatment days (pre-2 and pre-1), the day of vector administration (day 0), and days 1-4 and 21 after administration. Symptoms and physical examination were evaluated on every study day. Blood counts, clinical chemistry, and urinalysis were obtained on days pre-1, 1 , and 4 . Serum for antibody analysis was obtained on days pre-1 and 21. Nasal cytology was evaluated every day except day 0 . Pulmonary function tests and chest $\mathrm{x}$-rays were obtained on days pre- 2 and 4 . Serum for IL-6 measurement was obtained on days pre-1, 1, 4, and 21.

Cytology and inflammatory marker assessments. To evaluate cytology from the nasal mucosa, cells were obtained by nasal swab. Cells were dislodged from the swab in $1.5 \mathrm{ml}$ of EMEM. Cells were pelleted at 1,000 rpm for $5 \mathrm{~min}$ and resuspended in $0.5 \mathrm{ml}$ of EMEM. $60 \mu \mathrm{l}$ of cell suspension was cytospun onto slides and stained with Wright's stain. Samples were examined by light microscopy; 100-300 cells were counted and the cell differential was determined. IL-6 was measured in serum using an ELISA kit (R \& D Systems, Inc., Minneapolis, MN); the detection limit of the assay is $0.63 \mathrm{pg} / \mathrm{ml}$.

Immune response against lipid and DNA. Serum samples were analyzed for the presence of antibodies to the GL67:DOPE by ELISA method. The samples were checked before treatment and day 21 after treatment. Briefly, diluted serum was allowed to react with lipid coated onto microtiter plates and a horseradish peroxidase-conjugated antibody, specific for human IgG, was added. Binding was visualized by addition of enzyme substrate giving rise to a color reaction. An increase in optical density above the baseline sample was considered to be a positive response. Serum samples were analyzed for the presence of antibodies to DNA by a similar ELISA method. Diluted serum was allowed to react with DNA coated onto protamine-treated microtiter plates. Detection of bound antibody was as described above.

Measurement of nasal Vt. The transepithelial electrical potential difference across the nasal epithelium (Vt) was measured using previously described methods (5). The reference electrode was a subcutaneous needle connected with sterile normal saline solution to a silver-silver chloride pellet. The exploring electrode was a pediatric size 8 Teflon-coated latex Foley catheter (modified; Rüsch, Inc., Duluth, GA) with two side holes at the tip. The catheter was filled with Ringer's solution containing $(\mathrm{mM}) 135 \mathrm{NaCl}, 2.4 \mathrm{KH}_{2} \mathrm{PO}_{4}, 0.6 \mathrm{~K}_{2} \mathrm{HPO}_{4}$, $1.2 \mathrm{CaCl}_{2}, 1.2 \mathrm{MgCl}_{2}$, and 10 Hepes (titrated to $\mathrm{pH} 7.4$ with $\mathrm{NaOH}$ ) and was connected to a silver-silver chloride pellet. Voltage was measured with a voltmeter connected to a strip chart recorder. The rubber catheter was introduced into the nostril under telescopic guidance and the side holes of the catheter were placed under the inferior nasal 
turbinate $6 \mathrm{~cm}$ from the most caudal aspect of the columella. The catheter was then left in that position for the entire recording period. A continuous flow of solution at $5 \mathrm{ml} / \mathrm{min}$ was administered using an infusion pump. The following solutions were administered in order: Ringer's solution; Ringer's solution containing $100 \mu \mathrm{M}$ amiloride (Merck and Co., Inc., West Point, PA); a low $\mathrm{Cl}^{-}$solution (in which $135 \mathrm{mM}$ Na gluconate replaced $135 \mathrm{mM} \mathrm{NaCl}$ ) with $100 \mu \mathrm{M}$ amiloride plus $10 \mu \mathrm{M}$ terbutaline (Geigy Pharmaceuticals, Ardsley, NY); and a low $\mathrm{Cl}^{-}$solution with $100 \mu \mathrm{M}$ amiloride plus $10 \mu \mathrm{M}$ terbutaline plus $100 \mu$ M ATP (Sigma Chemical Co., St. Louis, MO). Each solution was perfused for a period of at least $5 \mathrm{~min}$. Once a stable $\mathrm{Vt}$ reading was obtained, perfusion with the next solution was begun. The entire procedure took $\sim 30-45 \mathrm{~min}$. Measurements of $\mathrm{Vt}$ were read by two investigators who were blinded; there were no discrepancies of $>2 \mathrm{mV}$. Values of $\mathrm{Vt}$ from the two readers were averaged.

$P C R$ and RT-PCR. Samples were collected by brushing the nasal cavity with a cytology brush. Samples from patients LC01-LC06 were prepared by swirling the collection brush in a sample tube containing an RNase inhibitor, then the brushes were discarded. The collection brushes for subsequent patient samples were retained and placed in RNase inhibitor. Samples were stored at $-80^{\circ} \mathrm{C}$ until ready for processing using the acid guanidinium-phenol-chloroform method (17). DNA was recovered from the organic phase using DNA STAT-60 (Tel-Test B, Inc., Friendswood, TX).

All amplification reactions were performed in a thermal cycler using Taq polymerase in a solution containing a final concentration of $10 \mathrm{mM}$ Tris- $\mathrm{HCl}, \mathrm{pH} 8.3,50 \mathrm{mM} \mathrm{KCl}, 1.75 \mathrm{mM} \mathrm{MgCl}_{2}, 0.01 \%$ gelatin, $200 \mathrm{mM}$ each dTTP, dATP, dGTP, dCTP, and primers that span the intron in the $5^{\prime}$ UTR. PCR amplification products were analyzed by electrophoresis in a 1.5\% LE agarose gel (FMC Corp. BioProducts, Rockland, ME). Semiquantitative reactions also contained $\left[{ }^{33} \mathrm{P}\right] \mathrm{dCTP}$ (New England Nuclear, Boston, MA). After photo documentation, the gels were dried, scanned onto a PhosphorImager (Molecular Dynamics, Sunnyvale, CA) and the results were quantified using analysis software. In addition to the study samples, water negative controls and positive control samples were run in each assay.

A reaction that amplifies a genomic sequence in exon 20 of the human CFTR gene was performed on all study samples as a positive control using $400 \mathrm{nM}$ of the primers hEx2OF and hEx2OR. Vector DNA was detected using a nested PCR protocol. Sample DNA $(1 \mu \mathrm{g})$ was added to the first round reaction which contained $500 \mathrm{nM}$ of each primer MP9 and MP10. The PCR products from the first round of amplification were diluted 1:100 in diethyl pyrocarbonate-treated water, and $10 \mu \mathrm{l}$ of this dilution of 1:1,000. The nested PCR reaction contained $125 \mathrm{nM}$ of each of the primers MP7 and MP8. The empty vector pCF1-Null was also detected using a nested PCR protocol containing $250 \mathrm{nM}$ of the primers MP25 and MP26 in the first round and $250 \mathrm{nM}$ of the primers MP27 and MP28 in the nested reaction.

An RT-PCR reaction testing for endogenous glyceraldehyde 3-phosphate dehydrogenase (GAPDH) message was performed on RNA samples to confirm the integrity of the mRNA. Total RNA was treated with DNase (Promega, Madison, WI) and cDNA was synthesized using SuperScript II RT and primed with $0.2 \mu \mathrm{g}$ of oligo dT primer (GIBCO BRL, Gaithersburg, MD). The RT reactions were run in duplicate with the second tube serving as a negative control where no RT enzyme was added. The cDNA was amplified in a PCR reaction using GAPDH primers obtained from a commercial kit (Clontech, Palo Alto, CA). Vector mRNA was detected using a nested RT-PCR protocol. Primer 977RT was used to prime the cDNA synthesis reaction using AMV-RT enzyme and reagents from a commercial kit (Invitrogen, San Diego, CA). RNA from 293 cells transfected with the pCF1-CFTR plasmid was used as a positive control. DNase treatment before analysis was not performed since an intron in the vector is spliced out of the mRNA and the resulting RTPCR products are distinguishable from the vector DNA amplification products by size. RT reactions were performed in duplicate with the second tube serving as a no RT negative control. The nested amplification reaction was performed as described above using $125 \mathrm{nM}$ of each of the primers 701 and 1338 in the first round and $125 \mathrm{nM}$ of each of the primers 750 and 1211 in the nested reaction.

Sequences of the primers used in this study are: hEX2OF: 5'AAGAACTGGATCAGGGAAGA 3'; hEX2OR: 5'TCCTTTTGCTCACCTGTGGT 3'; MP9: 5'GCGTTCGTCCTCACTCTC 3'; MP10: 5'GGCGCTGTCTGTATCCTT 3'; MP7: 5'GGATCGGAAAACCTCTC 3'; MP8: 5'GCCTGCCACACCTCAAG 3'; MP25: 5'GCGTTCGTCCTCACTCTC 3'; MP26: 5'ATAGAGCCCACCGCATCC 3'; MP27: 5'CACTTTGCCTTTCTCTCC 3'; MP28: 5'ATCCTCCCCCTTGCTGTC 3'; 977RT: 5'AGCGTTCCTCCTTCTTA $3^{\prime}$; 701: 5'CCTCACTCTCTTCCGCATCGCTGTC 3'; 1338: 5'GCCAGCTCTCTATCCCATTCTCTTTCCAAT 3'; 750: 5'CGGTTGAGGACAAACTCTTC 3'; and 1211:5'AAAAAGTTTGGAGACAACGC $3^{\prime}$.

\section{Results}

Part A: Effect of GL-67:DOPE in non-CF subjects. To evaluate the safety of the lipid vector alone in humans, we administered GL-67:DOPE to the nasal epithelium of non-CF subjects. Two subjects received $0.8 \mathrm{mg}$, two received $2 \mathrm{mg}$, and two received $4 \mathrm{mg}$ to one nostril. The contralateral nostril received sterile water, the vehicle for the lipid. The normal subjects were able to identify the nostril receiving lipid based on a particular odor or taste. At the highest dose of GL-67:DOPE ( $4 \mathrm{mg}$ ) one of the participants developed rhinorrhea and urticaria during infusion of the lipid into the left nostril. Most of the symptoms resolved within $1 \mathrm{~h}$ and all symptoms resolved within $11 \mathrm{~h}$. This subject had a history of cholinergic urticaria, a common condition in which urticaria is precipitated by many different stimuli including stress or exercise. Therefore, it is unclear as to whether the reaction was caused specifically by the GL-67:DOPE. However, for part B of the study we used the intermediate dose of $2 \mathrm{mg}$ lipid.

The clinical assessment, cytology of nasal washes, serum cytokines, and serum antibodies to DNA and GL-67:DOPE showed no significant alterations in any subject $21 \mathrm{~d}$ after treatment. To learn whether the lipids might injure the epithelium or produce nonspecific changes in ion transport, we measured the nasal voltage. Fig. 1 shows that there were no significant changes in basal $\mathrm{Vt}$ or the change in $\mathrm{Vt}$ produced by perfusion with a solution containing a low $\mathrm{Cl}^{-}$concentration $\left(\Delta \mathrm{Vt}_{\text {LowCl-Terb }}\right)$. Moreover, we saw no specific changes in response to amiloride or to perfusion with a solution containing a low $\mathrm{Cl}^{-}$concentration plus ATP (not shown). Comparison of basal measurements to measurements after treatment showed no changes nor were there any differences when the lipidtreated and the control nostril were compared.

These results suggest that administration of lipid alone to the nasal epithelium was safe in normal humans. Therefore we progressed to test the effect of administering DNA complexed to lipid in CF subjects.

Part B: Safety of DNA alone and DNA-lipid complexes in $C F$ subjects. In a double-blind fashion we administered 1.25 $\mathrm{mg}$ of pCF1-CFTR alone to the nasal epithelium of one nostril and $1.25 \mathrm{mg}$ pCF1-CFTR complexed with $2 \mathrm{mg}$ GL-67:DOPE to the nasal epithelium on the other side. We studied nine $\mathrm{CF}$ subjects. Evaluation of adverse events in the airway epithelium of patients with $\mathrm{CF}$ is complicated by the fact that these subjects have chronic nasal inflammation. During the course of the study the severity of inflammation varied, but we could discern no relationship between inflammation and vector administration. Cells obtained by nasal swabs showed a predomi- 
A

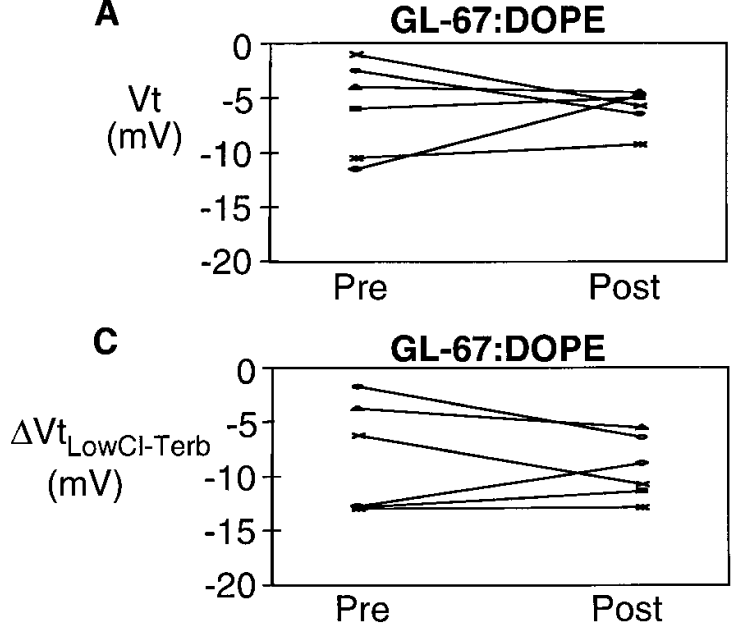

B

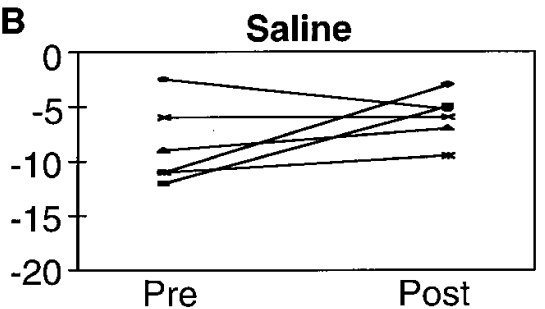

D

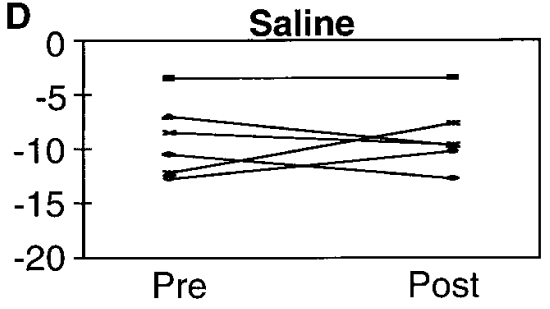

Figure 1. Nasal Vt measured in six normal subjects treated with either GL-67:DOPE ( $A$ and $C$ ) or vehicle $(B$ and $D)$. $A$ and $B$ show basal voltage and $C$ and $D$ show change in voltage produced by perfusion of a solution containing a low $\mathrm{Cl}^{-}$concentration and terbutaline $\left(\Delta \mathrm{Vt}_{\text {LowCl-Terb }}\right)$. Each set of symbols and lines are data for an individual subject. Data points show average values before treatment and $4 \mathrm{~d}$ after administration of lipid or water. There were no significant changes between pre- and postadministration values or between lipid and water groups. nance of squamous and respiratory epithelial cells with $0-10 \%$ neutrophils and $0-5 \%$ lymphocytes. There were no significant changes during the course of the study nor were there consistent differences between the right and left nostrils. There were no changes in any of the clinical assessments or cytology. We could detect no measurable levels of serum antibody to GL-67: DOPE or to pCF1-CFTR in any of the subjects. Pretreatment levels of IL-6 were lower in sera of normal patients studied in part A (range $0.63-2.5 \mathrm{pg} / \mathrm{ml}$ ) than in the $12 \mathrm{CF}$ patients studied in parts $B$ and $C(1.75-12 \mathrm{pg} / \mathrm{ml})$. The higher basal levels of IL-6 are probably due to the chronic inflammation in CF. In three of the nine CF subjects (LC03, LC05, and LC07) there was a slight increase in serum IL-6 levels at day 4. On day 21 the serum level of IL-6 remained elevated in one subject, returned to basal values in one subject, and were not measured in one subject.

These data suggest that there were little if any systemic or local adverse effects that could be attributed to DNA or DNAlipid administration. The significance of the slight increase in levels of IL-6 in three subjects is uncertain and it is not clear if it resulted from vector administration. Future studies will be required to evaluate the effect of repetitive administration and administration to the lung.
Part B: Evaluation of electrophysiologic changes after administration of DNA and DNA-lipid complexes. The goal of gene transfer in $\mathrm{CF}$ is to correct the CFTR $\mathrm{Cl}^{-}$channel defect in airway epithelia. The presence of functional CFTR in the epithelium can be evaluated electrically by measuring $\mathrm{Vt}$. There are two main changes in electrical properties in CF epithelia: the basal Vt is increased and there is no hyperpolarization of $\mathrm{Vt}$ when the apical membrane is perfused with a solution containing a low concentration of $\mathrm{Cl}^{-}$and a cAMP agonist such as terbutaline $\left(\Delta \mathrm{Vt}_{\text {LowCl-Terb }}\right)$. We found no significant change in basal $\mathrm{Vt}$ or the change in $\mathrm{Vt}$ during perfusion with amiloride in any of the nine subjects in either nostril after treatment. Moreover, there were no significant alterations in the voltage induced by perfusion with a solution containing a low concentration of $\mathrm{Cl}^{-}$and ATP, a maneuver that evaluates the presence of $\mathrm{Cl}^{-}$channels different from CFTR.

The electrical property that is most sensitive and specific for the presence of functional CFTR is the $\Delta \mathrm{Vt}_{\text {LowCl-Terb. }}$. Fig. 2 shows average measurements of $\Delta \mathrm{Vt}_{\text {LowCl-Terb }}$ for each individual subject before and after administration of complexes of pCF1-CFTR/GL-67:DOPE or pCF1-CFTR alone. During the pretreatment period, $\Delta \mathrm{Vt}_{\text {LowCl-Terb }}$ showed either little change or a depolarization; the mean $\Delta \mathrm{Vt}_{\text {LowCl-Terb }}$ was $+2 \mathrm{mV}$ to +3
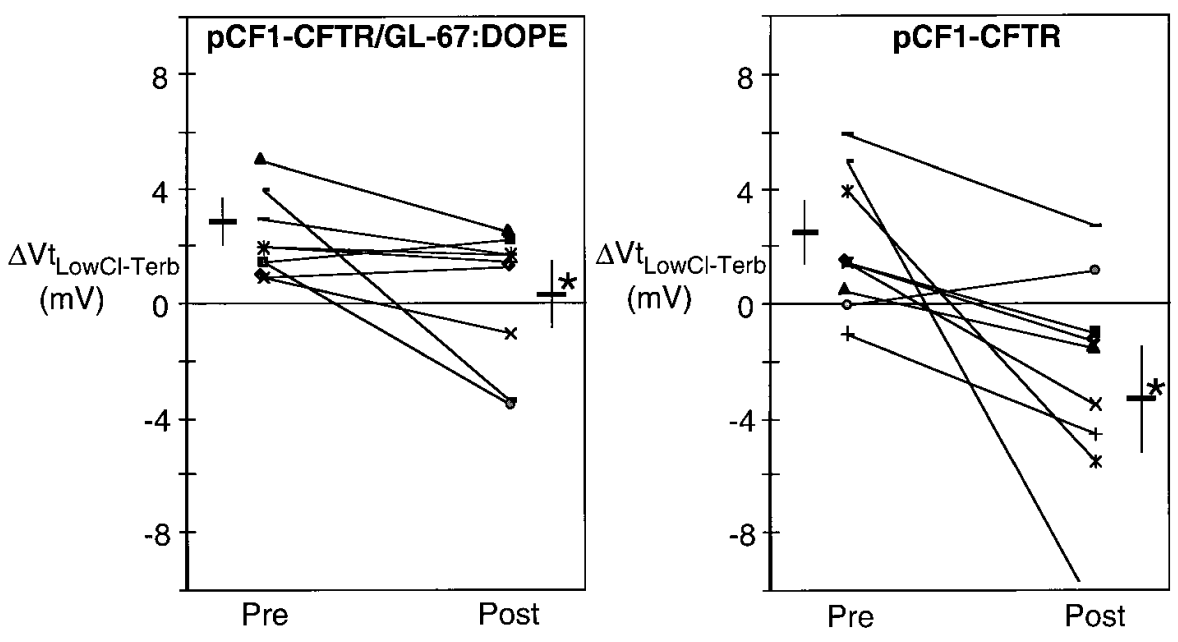

Figure 2. Change in voltage produced by perfusion of a solution containing a low $\mathrm{Cl}^{-}$concentration and terbutaline $\left(\Delta \mathrm{Vt}_{\text {LowCl-Terb }}\right)$. Data are pretreatment values (average of two measurements before treatment) and posttreatment values (average of values for $4 \mathrm{~d}$ after vector administration). Each set of symbols and lines are from a different subject. Large bars and standard error bars at sides of each panel show average changes in $\Delta \mathrm{Vt}_{\text {LowCl-Terb }}$ for all nine subjects. $* P<0.05$ compared with pretreatment values. 

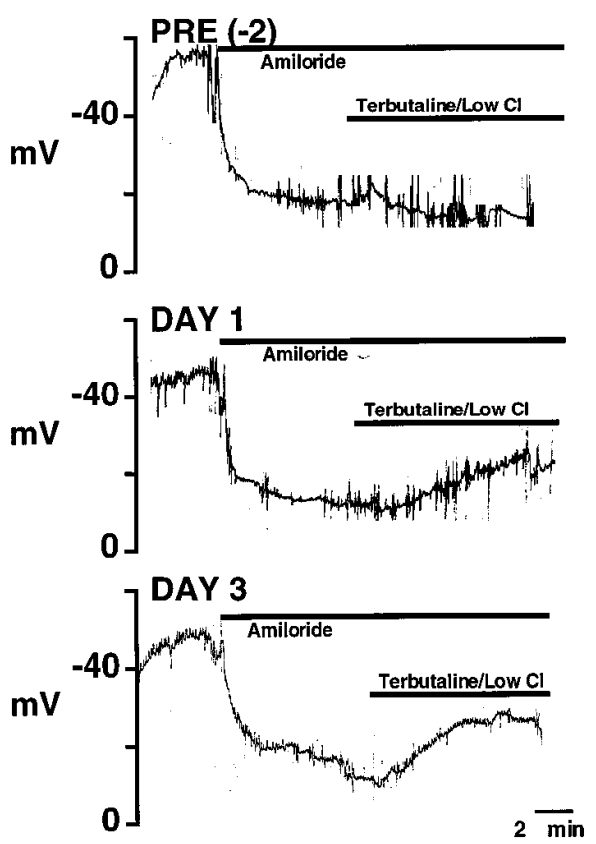
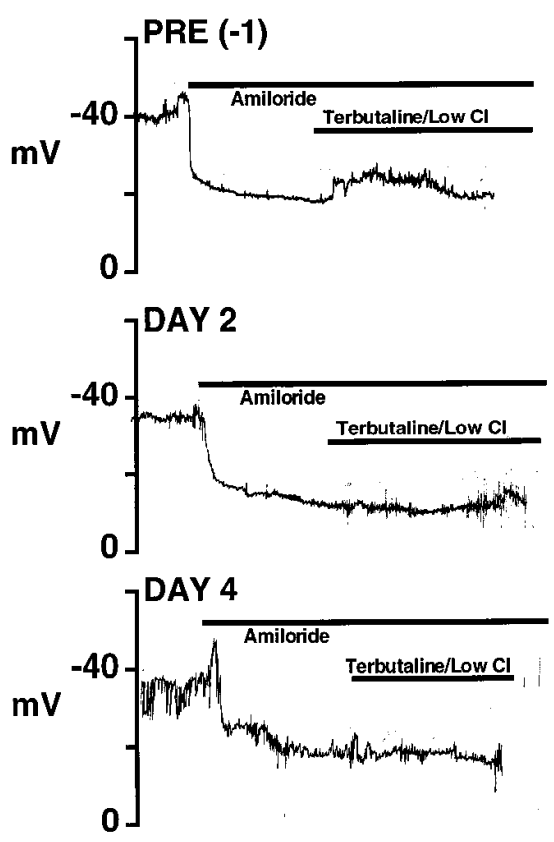

Figure 3. Recordings of Vt from subject LC08 before and after administration of pCF1-CFTR. Measurements were made on two pretreatment days and $4 \mathrm{~d}$ after administration. Tracings were obtained during continuous perfusion with Ringer's solution; times during which solution contained $100 \mu \mathrm{M}$ amiloride or a low $\mathrm{Cl}^{-}$solution with $100 \mu \mathrm{M}$ amiloride plus $10 \mu \mathrm{M}$ terbutaline are indicated.
$\mathrm{mV}$ in both nostrils. These values are consistent with previous measurements in $\mathrm{CF}$ subjects $(4,5,13)$. After administration of DNA or DNA-lipid complex, we observed substantial variability between individual subjects. However, both groups showed a statistically significant correction in $\Delta \mathrm{Vt}_{\text {LowCl-Terb. }}$ Although it appeared that there was a trend for pCF1-CFTR alone to produce a larger change in $\Delta \mathrm{Vt}_{\text {LowCl-Terb }}$, there was no statistical difference between the pCF1-CFTR and pCF1CFTR/GL-67:DOPE groups.

We also examined changes with time during the $4 \mathrm{~d}$ after treatment. Fig. 3 shows an example of the Vt measurements from the pCF1-CFTR-treated nostril of one subject (LC08). On the two pretreatment days there was no sustained $\mathrm{Vt}$ response to perfusion with a solution containing a low $\mathrm{Cl}^{-}$concentration and terbutaline. Note that a transient hyperpolarization was sometimes observed in CF subjects (day pre-1 shows an example) $(5,13)$. However, as described in Methods, measurements were made after any transient changes had subsided. On days 1 and 3 after administration of pCF1-CFTR,
$\Delta \mathrm{Vt}_{\text {LowCl-Terb }}$ hyperpolarized, a response consistent with correction of the $\mathrm{CF}$ electrophysiologic defect. However, it is interesting that the changes were not observed on every day; on days 2 and 4 there was no change in $\Delta \mathrm{Vt}_{\text {LowCl-Terb }}$. We show these data from patient LC08 because they are representative in that with both DNA and DNA-lipid the response was observed to vary from day to day. The variability in correction of $\Delta \mathrm{Vt}_{\text {LowCl-Terb }}$ might be explained by day-to-day variability in the placement of the recording electrode and/or spatial variability in the level of gene transfer throughout the nasal epithelium.

We also analyzed the $\Delta \mathrm{Vt}_{\text {LowCl-Terb }}$ with time for all the subjects (Fig. 4). The average correction was relatively constant with time for subjects treated with pCF1-CFTR. However, there was a trend for $\Delta \mathrm{Vt}_{\text {LowCl-Terb }}$ to become progressively more negative (hyperpolarized) with time after DNA-lipid administration. Although the number of subjects is small, this trend suggests that the complex with lipid might have delayed gene transfer. This result suggests the possibility that com-

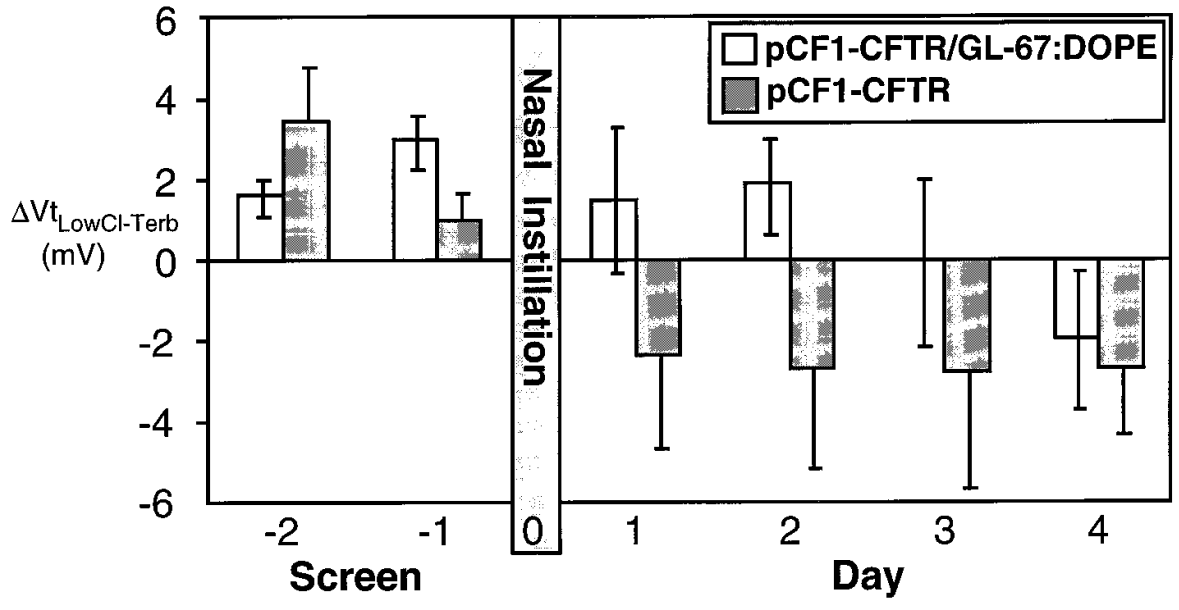

Figure 4. Time-dependent changes in $\Delta \mathrm{Vt}_{\text {LowCl-Terb }}$. Data are mean $\pm \mathrm{SEM}$ of values for all nine subjects determined on the two pretreatment and four posttreatment days. Open bars are data from nostril treated with pCF1-CFTR/GL67:DOPE and shaded bars are data from nostril treated with pCF1-CFTR alone. 


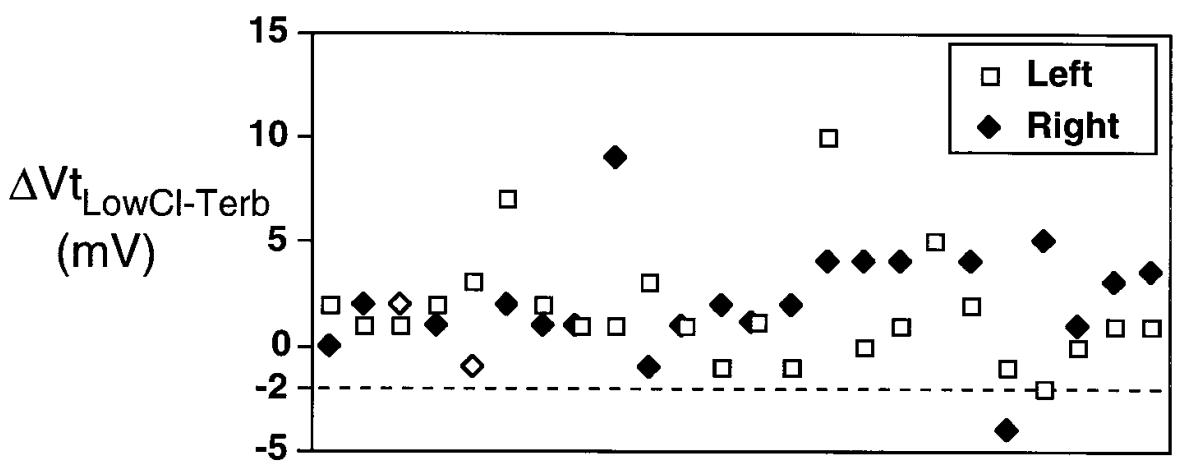

Figure 5. Individual values of $\Delta \mathrm{Vt}_{\text {LowCl-Terb }}$ measured during pretreatment period from $12 \mathrm{CF}$ subjects. Values from each subject on two different days are shown. Squares show data from left nostril and diamonds are from right nostril. plexes of DNA/GL-67:DOPE might have shown a greater correction if measurements had been made at times $>4 \mathrm{~d}$.

Another way to assess whether administration of the DNA-lipid complex produced a significant correction of $\Delta \mathrm{Vt}_{\text {LowCl-Terb }}$ is to evaluate the number of days on which $\Delta \mathrm{Vt}_{\text {LowCl-Terb }}$ hyperpolarized. Based on our previous studies, we considered that $\Delta \mathrm{Vt}_{\text {LowCl-Terb }}$ hyperpolarized if perfusion with the solution containing a low $\mathrm{Cl}^{-}$concentration caused $\mathrm{Vt}$ to change in the negative direction by $2 \mathrm{mV}$ or more. Fig. 5 shows all of the pretreatment values of $\Delta \mathrm{Vt}_{\text {LowCl-Terb }}$ for the 12 subjects who participated in parts $\mathrm{B}$ and $\mathrm{C}$. The data show that in 2 of 47 pretreatment measurements, $\Delta \mathrm{Vt}_{\text {LowCl-Terb }}$ hyperpolarized by $2 \mathrm{mV}$ or more. In contrast, after treatment with DNA-lipid, 8 of 36 (22\%) measurements of $\Delta \mathrm{Vt}_{\text {LowCl-Terb }}$ from the treated nostrils showed hyperpolarization of $2 \mathrm{mV}$ or more $\left(P<0.001\right.$ compared with all pretreatment values, $\chi^{2}$ analysis $)$. In nostrils treated with pCF1-CFTR alone, 14 of $36(39 \%)$ measurements of $\Delta \mathrm{Vt}_{\text {LowCl-Terb }}$ showed hyperpolarization of $2 \mathrm{mV}$ or more $(P<0.001$ compared with pretreatment values, $\chi^{2}$ analysis).

These data indicate that both DNA alone and DNA-lipid complexes produced gene transfer to the nasal epithelium which resulted in a significant correction of $\Delta \mathrm{Vt}_{\text {LowCl-Terb }}$. However, we did not observe a significant difference between the two vector systems.
Part B: PCR and RT-PCR after administration of DNA and DNA-lipid complexes. $4 \mathrm{~d}$ after vector administration, we brushed the nasal epithelium to collect cells for PCR and RTPCR, a maneuver that disrupts the epithelium and precludes subsequent measurements of $\mathrm{Vt}$. We were able to amplify vector-specific CFTR DNA from eight of nine nostrils treated with pCF1-CFTR/GL-67:DOPE complexes and nine of nine nostrils treated with pCF1-CFTR alone. In contrast, we could not detect a signal in any of the nostrils that received the lipid only in part A of the study. Our brushed sample collected $\sim 10^{6}$ cells $4 \mathrm{~d}$ after administration.

We attempted RT-PCR on all of the samples. However, in the first six subjects we believe the RNA was degraded because we could detect neither endogenous transcripts of GAPDH nor vector-encoded transcripts. This may be because the sample size was small and/or abundant RNases in the nose may have degraded transcripts. In the last three subjects, GAPDH transcripts were detected by RT-PCR amplification demonstrating integrity of these samples. In these samples, RT-PCR for vector-encoded CFTR transcripts was positive in one of three nostrils treated with DNA-lipid and two of three nostrils treated with DNA alone (Fig. 6). Despite the technical difficulties in six of the nine subjects, the limited data from RT-PCR support the electrophysiologic data which showed correction with both DNA and DNA-lipid.

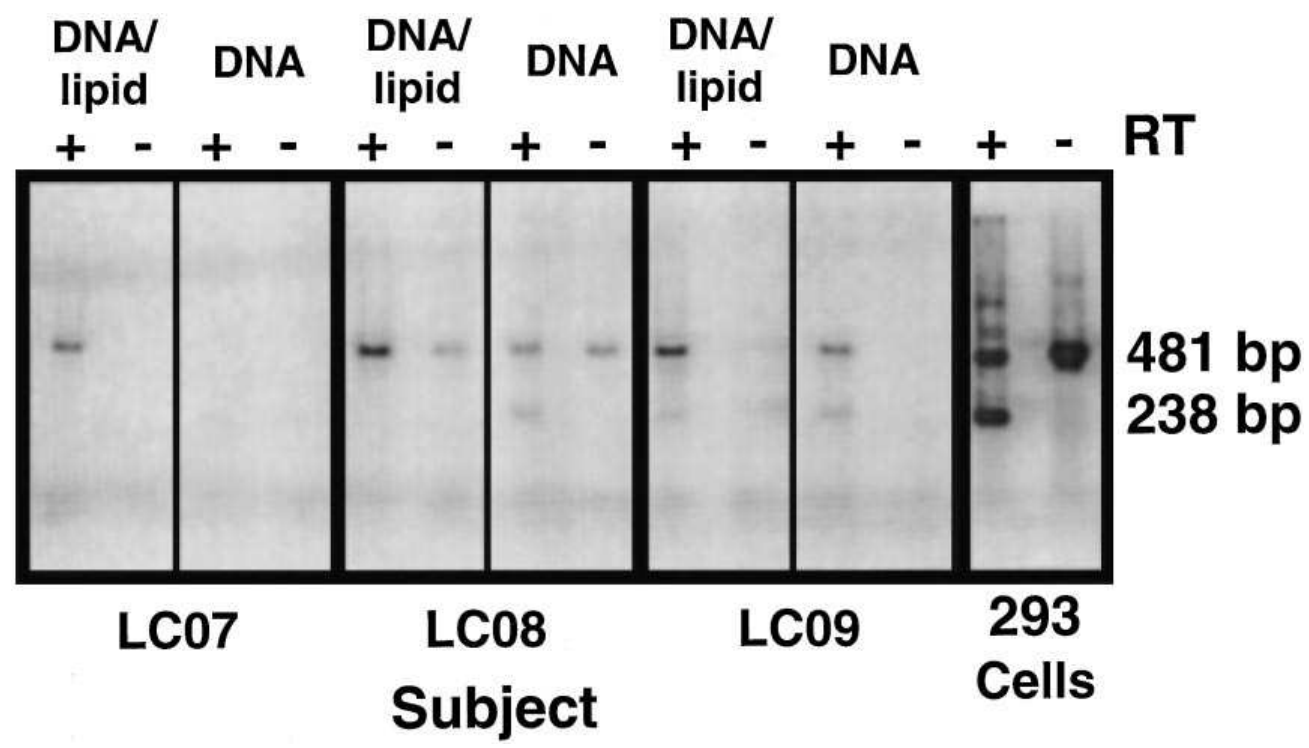

Figure 6. RT-PCR from three subjects. Nostrils treated with DNA-lipid or DNA alone are indicated. Presence and absence of RT are indicated. Lanes marked 293 cells are a positive control. Band at $481 \mathrm{bp}$ is product amplified from plasmid; band at $238 \mathrm{bp}$ is specific for RNA due to removal of intron by splicing. Note also that the 481-bp band is present in samples not treated with RT. 
Part C: Evaluation of gene transfer with $p C F 1-C F T R$ versus $p N u l l$. We were surprised to find that pCF1-CFTR alone was as effective as the pCF1-CFTR/GL-67:DOPE complexes. We considered the possibility that gene transfer in the nostril treated with pCF1-CFTR alone could have resulted from contamination by lipid administered to the contralateral nostril. This at first seemed unlikely based on the known direction of mucociliary clearance (18), on our previous studies using methylene blue (2), and on our previous studies in which adenovirus was administered to one nostril and not detected in the other (5). These data all suggested very little crossover from one nostril to the other. However, to test this possibility further, we studied three additional subjects with CF. We administered $1.25 \mathrm{mg}$ of pCF1-CFTR alone to one nostril and an identical plasmid that did not encode CFTR (pNull) to the other nostril in a blinded fashion. We observed no changes in clinical assessments, cytology, or antibodies in any subject. Two of the three subjects (LC11 and LC12) had slight increase in serum IL-6 level on day 4 which remained elevated on day 21 in one subject and returned to basal values in the other subject.

To assess the possibility of cross-contamination, we developed a semiquantitative PCR assay for both pCF1-CFTR and pNull. An example of the standardization of the assay is shown in Fig. $7 A$. Fig. 7, $B$ and $C$, shows the results of the PCR analysis for the three subjects. Both pCF1-CFTR and pNull were amplified from both nostrils. However, the amount of pCF1CFTR DNA amplified was always higher in one of the nostrils. The amount of pNull amplified was higher in the contralateral nostril.

Fig. $7 D$ shows measurements of $\Delta \mathrm{Vt}_{\text {LowCl-Terb }}$ in the three subjects. $\Delta \mathrm{Vt}_{\text {LowCl-Terb }}$ hyperpolarized in the right nostril of subject LC10 and the left nostril of LC12. There was no hyperpolarization in either nostril of subject LC11. The nostrils in which $\Delta \mathrm{Vt}_{\text {LowCl-Terb }}$ hyperpolarized were the nostrils which on day 4 yielded the higher levels of pCF1-CFTR DNA (Fig. 7 B) and the lower levels of pNull (Fig. $7 C$ ). However, when we unblinded the study, we found that subject LC10 was randomized to receive pCF1-CFTR to the left nostril even though we found the highest levels of pCF1-CFTR DNA on the right nostril and correction of $\Delta \mathrm{Vt}_{\text {LowCl-Terb }}$ on the right nostril. We cannot exclude the possibility of an error at the time of administration. However, even in the absence of an error it appears that the greater PCR signal from the CFTR DNA correlated with the nostril that showed correction of $\Delta \mathrm{Vt}_{\mathrm{LowCl}-\mathrm{Terb}}$.

\section{Discussion}

Our results show that a nonviral vector can transfer CFTR cDNA to CF airway epithelia in vivo and partially correct the $\mathrm{Cl}^{-}$transport defect that characterizes the disease. Unlike prior studies of cationic lipid or viral vectors in humans, DNA alone was used as a control. In this nasal model of direct instillation, the DNA-lipid complex was no more effective than DNA alone.

In a previous study, Caplen et al. (13) administered complexes of $300 \mu \mathrm{g}$ DNA with $1.5 \mathrm{mg}$ DC-Chol:DOPE per nostril at 10-min intervals over $7 \mathrm{~h}$. Although not statistically significant, the data showed a partial correction of $\Delta \mathrm{Vt}_{\text {LowCl-Terb }}$ and positive RT-PCR results. The control group for that study consisted of six different $\mathrm{CF}$ patients that received the equivalent dose of DC-Chol:DOPE alone. None of the subjects received
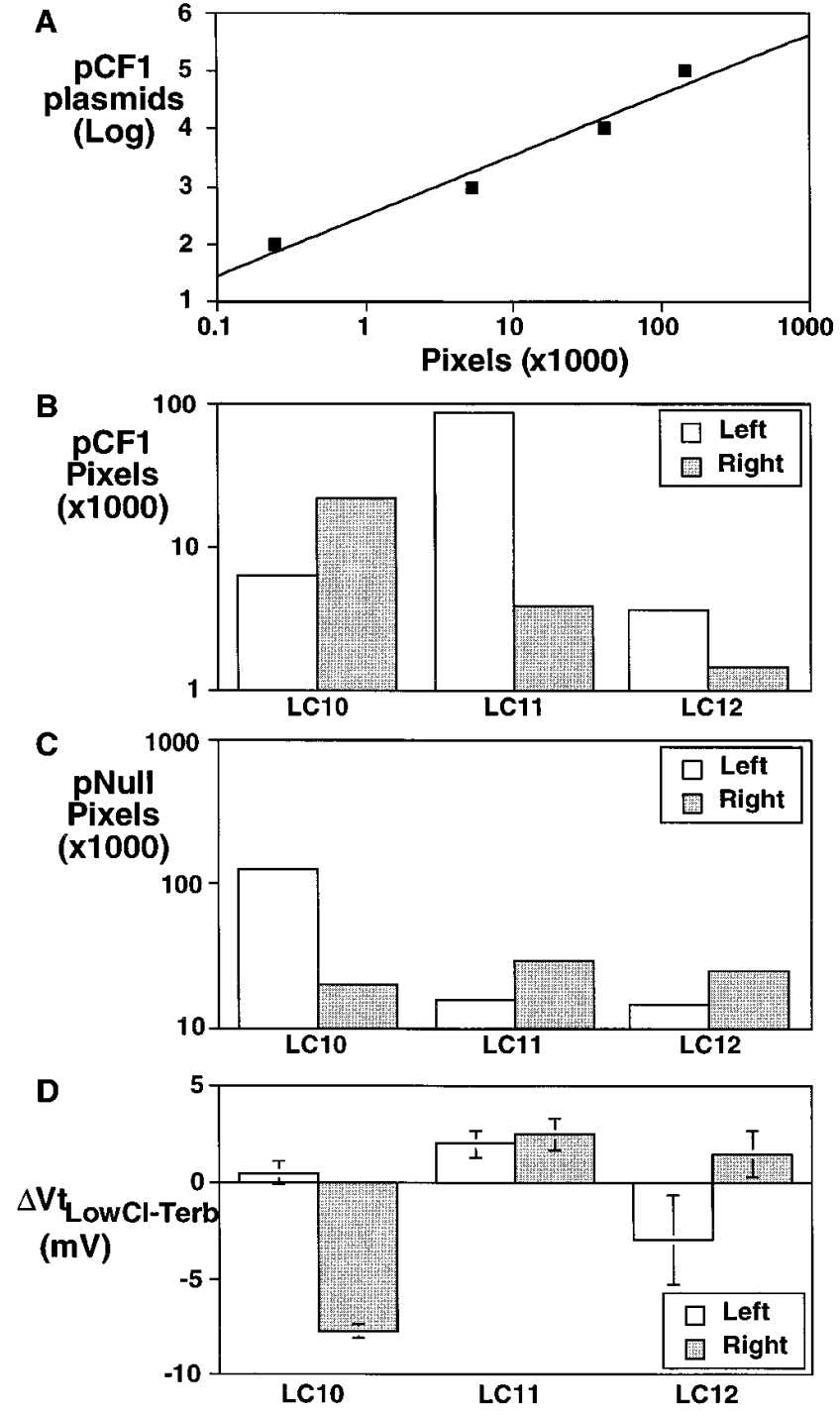

Figure 7. PCR of DNA and voltage changes in subjects treated with pCF1-CFTR and pNull. $A$ shows standardization of PCR, relating amount of plasmid added to the reaction versus pixels of signal detected. $B$ and $C$ show the pixels of signal from brush of left (open bars) and right (shaded bars) nostrils of three CF subjects. $D$ shows average $\Delta \mathrm{Vt}_{\text {LowCl-Terb }}$ measured during the $4 \mathrm{~d}$ after administration of pCF1-CFTR or pNull. pCF1-CFTR was delivered to the left nostril in all three patients.

DNA alone. There are reports of two other studies in humans in which DNA-lipid was administered to the nasal mucosa of CF subjects. Gill et al. (14) used 40 or $400 \mu \mathrm{g}$ of a plasmid encoding CFTR complexed with DC-Chol:DOPE and Porteous et al. (15) delivered complexes of $400 \mu \mathrm{g}$ plasmid with $2.4 \mathrm{mg}$ DOTAP. The studies also suggest that there was some partial correction of $\mathrm{Cl}^{-}$transport and positive results from RT-PCR analysis of biopsy samples. However, in neither of those studies was DNA administered without lipid.

We chose GL-67:DOPE as our lipid vector for these studies based on an extensive screening study in mice (16). DNA complexed with many different cationic lipids was administered to the lungs of mice and gene transfer was evaluated by 
measuring reporter gene expression in the whole lung. In those studies complexes of DNA/GL-67:DOPE outperformed DNA alone and several other cationic lipids. Our current results raise questions about limitations of this assay for screening purposes. First, the cells expressing the reporter included both airway and peripheral cells but the relative amounts of each were not known. The airway epithelia represent a small fraction of total lung weight. Thus, it is likely that substantial gene transfer occurred in cells other than airway epithelial cells. Second, in this assay it is difficult to differentiate between low level expression in many cells, versus very high level transgene expression in a few cells. For $\mathrm{CF}$, the former would be preferable since very little CFTR expression is required to generate transepithelial $\mathrm{Cl}^{-}$transport. Third, it could be that optimization of gene transfer to murine cells might be different from that required for human cells. Given these considerations, how might multiple lipids and formulations of nonviral vectors be screened? Perhaps the mouse lung assay could be used to identify promising lipids which could then be tested in human epithelia in vitro, and then human airway epithelia in patients. It is also important to remember that our current studies were done in airway epithelia in the nose and the transfection efficiency may be either better or worse than that in the lower airways. Additional studies will be required to assess the efficiency of GL-67:DOPE as a vector in intrapulmonary airways.

In previous studies we and others have found that there are several barriers to efficient cationic lipid-mediated gene transfer (19). These steps include the formation of heterogeneous complexes, binding to the cells, internalization, escape from endosomes, release of DNA from the lipid complex, and entry into the nucleus. In preliminary studies, we found that human airway epithelia that had developed into a mature differentiated epithelium did not efficiently bind to DNA-cationic lipid complexes. The resistance to transfection occurred as the epithelia developed tight junctions and differentiated. In another study Matsui et al. (20) found decreased binding and decreased uptake of DNA-LipofectACE complexes by islands of differentiated airway epithelia in vitro. These in vitro data suggest that transfection of airway epithelia with at least some of the current DNA-lipid formulations is inefficient.

Our data showing that DNA alone can mediate gene transfer to airway epithelia are supported by some studies in animals. Meyer et al. (21) compared delivery of DNA alone to complexes of DNA with DOTMA-DOPE and DOTAP. They found that neither cationic lipid enhanced gene expression over that observed with DNA alone. However, they did find that complexes prevented rapid degradation of the DNA. Those results might explain the trend we observed for correction of $\Delta \mathrm{Vt}_{\text {LowCl-Terb }}$ at later times when we used DNAlipid complexes. Malone (22) delivered DNA alone and complexes of DNA with 1,2-dioleoyl-3-dimethylammonium-propane (DODMP) and found that cationic lipid-mediated gene transfer was more effective than DNA alone in delivering genes to the lung parenchyma. However, in the airways the results were reversed, with DNA generating greater gene transfer than DNA-DODMP complexes. However, those reports used different lipids, making direct comparison to GL-67/DOPE difficult.

These results raise the interesting question of whether DNA alone should be considered for gene transfer to airway epithelia. In muscle, DNA alone is more effective for gene transfer than DNA-lipid complexes $(23,24)$. Likewise, in a mouse melanoma, DNA alone was more effective than complexes of DNA with DC-Chol:DOPE or 3:1 DOSPA (2,2-dioleoyloxy- $N$-[2(spermine-carboxamide)ethyl]- $N, N$-dimethyl-11propanaminiumtrifluoroacetate):DOPE (Lipofectamine) (25). In addition, recent reports suggest that DNA alone can achieve significant gene transfer in liver (26-28), heart (29), and synovium (30). Use of DNA alone in the lung might have the advantage of low toxicity $(12,21)$. However, DNA alone may have limitations for use in airways. First, the required dose might be quite large. Second, aerosolization of DNA causes it to fragment (31). However, our data suggest that plasmid-based systems may be feasible vectors and that further work should focus on developing formulations and agents that may compact and protect the DNA. For example, previous studies have shown that cationic lipids can protect plasmid DNA from fragmentation during aerosolization (31).

The ability of both DNA-cationic lipid complexes and DNA alone to accomplish gene transfer to airway epithelia in vivo is promising. However, our data underscore the point that additional investigation will be required to develop "gene transfer" to the point at which it can be considered "gene therapy."

\section{Acknowledgments}

We thank Aurita Puga, Theresa Mayhew, Jennifer Tousignant, Ronald Scheule, Simon Eastman, David Harris, Nicholas Wan, Edward Lee, David McNeilly, Mireille Rosenberg, and Darshana Jani. We are especially indebted to the patients with $\mathrm{CF}$ and other participants who volunteered for these studies.

This work was supported by grants from the National Heart Lung and Blood Institute, the Cystic Fibrosis Foundation, a General Clinical Research Center Program for the National Center for Research Resources, the Howard Hughes Medical Institute, and by Genzyme Corporation. We appreciate the help and assistance of the CF Clinical Center and the General Clinical Research Center. J. Zabner is a fellow of the Parker B. Francis Families Foundation and of the Roy J. Carver Charitable Trust. M.J. Welsh is an Investigator of the Howard Hughes Medical Institute.

\section{References}

1. Welsh, M.J., L.-C. Tsui, T.F. Boat, and A.L. Beaudet. 1995. Cystic fibrosis. In The Metabolic and Molecular Basis of Inherited Disease. C.R. Scriver, A.L. Beaudet, W.S. Sly, and D. Valle, editors. McGraw-Hill, Inc., New York. 3799-3876.

2. Zabner, J., L.A. Couture, R.J. Gregory, S.M. Graham, A.E. Smith, and M.J. Welsh. 1993. Adenovirus-mediated gene transfer transiently corrects the chloride transport defect in nasal epithelia of patients with cystic fibrosis. Cell. 75:207-216.

3. Crystal, R.G., N.G. McElvaney, M.A. Rosenfeld, C.S. Chu, A. Mastrangeli, J.G. Hay, S.L. Brody, H.A. Jaffe, N.T. Eissa, and C. Danel. 1994. Administration of an adenovirus containing the human CFTR cDNA to the respiratory tract of individuals with cystic fibrosis. Nat. Genet. 8:42-51.

4. Hay, J.G., N.G. McElvaney, J. Herena, and R.G. Crystal. 1995. Modification of nasal epithelial potential differences of individuals with cystic fibrosis consequent to local administration of a normal CFTR cDNA adenovirus gene transfer vector. Hum. Gene Ther. 6:1487-1496.

5. Zabner, J., B.W. Ramsey, D.P. Meeker, M.I. Aitken, R.P. Balfour, R.L. Gibson, J. Launspach, R.A. Moscicki, S.M. Richards, T.A. Standaert, et al. 1996. Repeat administration of an adenovirus vector encoding CFTR to the nasal epithelium of patients with cystic fibrosis. J. Clin. Invest. 97:1504-1511.

6. Knowles, M.R., K.W. Hohneker, Z. Zhou, J.C. Olsen, T.L. Noah, P.C. Hu, M.W. Leigh, J.F. Engelhardt, L.J. Edwards, K.R. Jones, et al. 1995. A controlled study of adenoviral-vector-mediated gene transfer in the nasal epithelium of patients with cystic fibrosis. N. Engl. J. Med. 333:823-831.

7. Stribling, R., E. Brunette, D. Liggitt, K. Gaensler, and R. Debs. 1992. Aerosol gene delivery in vivo. Proc. Natl. Acad. Sci. USA. 89:11277-11281.

8. Canonico, A.E., J.T. Conary, B.O. Meyrick, and K.L. Brigham. 1994. Aerosol and intravenous transfection of human $\alpha 1$-antitrypsin gene to lungs of rabbits. Am. J. Respir. Cell Mol. Biol. 10:24-29. 
9. Alton, E.W., P.G. Middleton, N.J. Caplen, S.N. Smith, D.M. Steel, F.M. Munkonge, P.K. Jeffery, D.M. Geddes, S.L. Hart, R. Williamson, et al. 1993. Non-invasive liposome-mediated gene delivery can correct the ion transport defect in cystic fibrosis mutant mice. Nat. Genet. 5:135-142.

10. Hyde, S.C., D.R. Gill, C.F. Higgins, A.E. Trezise, L.J. MacVinish, A.W. Cuthbert, R. Ratcliff, M.J. Evans, and W.H. Colledge. 1993. Correction of the ion transport defect in cystic fibrosis transgenic mice by gene therapy. Nature (Lond.). 362:250-255.

11. Levy, M.Y., L.G. Barron, K.B. Meyer, and F.C. Szoka, Jr. 1996. Characterization of plasmid DNA transfer into mouse skeletal muscle: evaluation of uptake mechanism, expression and secretion of gene products into blood. Gene Ther. 3:201-211.

12. Tsan, M.F., J.E. White, and B. Shepard. 1995. Lung-specific direct in vivo gene transfer with recombinant plasmid DNA. Am. J. Physiol. 268:L1052L1056.

13. Caplen, N.J., E.W. Alton, P.G. Middleton, J.R. Dorin, B.J. Stevenson, X. Gao, S.R. Durham, P.K. Jeffery, M.E. Hodson, C. Coutelle, et al. 1995. Liposome-mediated CFTR gene transfer to the nasal epithelium of patients with cystic fibrosis. Nat. Med. 1:39-46.

14. Gill, D.R., K.W. Southern, K.A. Mofford, T. Seddon, L. Huang, F. Sorgi, A. Thomson, L.J. MacVinish, R. Ratcliff, D. Bilton, et al. 1997. A placebo-controlled study of liposome-mediated gene transfer to the nasal epithelium of patients with cystic fibrosis. Gene Ther. 4:199-209.

15. Porteous, D.J., J.R. Dorin, G. McLachlan, H. Davidson-Smith, H. Davidson, B.J. Stevenson, A.C. Carothers, W.A.H. Wallace, S. Moralee, C. Hoenes, et al. 1997. Evidence for safety and efficacy of DOTAP cationic liposome mediated CFTR gene transfer to the nasal epithelium of patients with cystic fibrosis. Gene Ther. 4:210-218.

16. Lee, E.R., J. Marshall, C.S. Siegel, C. Jiang, N.S. Yew, M.R. Nichels, J.B. Nietupski, R.J. Ziegler, M. Lane, K.X. Wang, et al. 1996. Detailed analysis of structures and formulations of cationic lipids for efficient gene transfer to the lung. Hum. Gene Ther. 7:1701-1717.

17. Chomczynski, P., and N. Sacchi. 1987. Single-step method of RNA isolation by acid guanidinium thiocyanate-phenol-chloroform extraction. Anal. Biochem. 162:156-159.

18. Nuutinen, J. 1996. Asymmetry in the nasal mucociliary transport rate. Laryngoscope. 106:1424-1428.

19. Zabner, J., A.J. Fasbender, T. Moninger, K.A. Poellinger, and M.J.
Welsh. 1995. Cellular and molecular barriers to gene transfer by a cationic lipid. J. Biol. Chem. 270:18997-19007.

20. Matsui, H., L.G. Johnson, S.H. Randell, and R.C. Boucher. 1997. Loss of binding and entry of liposome-DNA complexes decreases transfection efficiency in differentiated airway epithelial cells. J. Biol. Chem. 272:1117-1126.

21. Meyer, K.B., M.M. Thompson, M.Y. Levy, L.G. Barron, and F.C. Szoka, Jr. 1995. Intratracheal gene delivery to the mouse airway: characterization of plasmid DNA expression and pharmacokinetics. Gene Ther. 2:450-460.

22. Malone, R.W. 1996. Toxicology of non-viral gene transfer. IBC: Non-viral Genetic Therapeutics.

23. Wolff, J.A., R.W. Malone, P. Williams, W. Chong, G. Acsadi, A. Jani, and P.L. Felgner. 1990. Direct gene transfer into mouse muscle in vivo. Science (Wash. DC). 247:1465-1468.

24. Tripathy, S.K., E.C. Svensson, G.B. Black, E. Goldwasser, M. Margalith, P.M. Hobart, and J.M. Leiden. 1996. Long-term expression of erythropoietin in the systemic circulation of mice after intramuscular injection of a plasmid DNA vector. Proc. Natl. Acad. Sci. USA. 93:10876-10880.

25. Yang, J.P., and L. Huang. 1996. Direct gene transfer to mouse melanoma by intratumor injection of free DNA. Gene Ther. 3:542-548.

26. Hickman, M.A., R.W. Malone, K. Lehmann-Bruinsma, T.R. Sih, D. Knoell, F.C. Szoka, R. Walzem, D.M. Carlson, and J.S. Powell. 1994. Gene expression following direct injection of DNA into liver. Hum. Gene Ther. 5:14771483.

27. Budker, V., G. Zhang, S. Knechtle, and J.A. Wolff. 1996. Naked DNA delivered intraportally expresses efficiently in hepatocytes. Gene Ther. 3:593-598.

28. Wolff, J.A., V. Budker, G. Zhang, and S. Knechtle. 1996. Naked DNA delivered intraportally expresses efficiently in hepatocytes. Cold Spring Harbor Gene Therapy Meeting. 353. (Abstr.)

29. Buttrick, P.M., A. Kass, R.N. Kitsis, M.L. Kaplan, and L.A. Leinwand 1992. Behavior of genes directly injected into the rat heart in vivo. Circ. Res. 70 193-198.

30. Nita, I., S.C. Ghivizzani, J. Galea-Lauri, G. Bandara, H.I. Georgescu, P.D. Robbins, and C.H. Evans. 1996. Direct gene delivery to synovium. An evaluation of potential vectors in vitro and in vivo. Arthritis Rheum. 39:820-828.

31. Eastman, S.-J., M.J. Lukason, J.D. Tousignant, H. Murray, M.D. Lane J.A. St. George, G.Y. Akita, M. Cherry, S.H. Cheng, and R.K. Scheule. 1997. A concentrated and stable aerosol formulation of cationic lipid: DNA complexes giving high level gene expression in mouse lung. Hum. Gene Ther. 8:765-773. 